\title{
Interracial differences in prostate cancer progression among patients from the United States, China and Japan
}

\author{
Haiyen E Zhau, Qinlong Li and Leland WK Chung \\ Asian Journal of Andrology (2013) 15, 705-707; doi:10.1038/aja.2013.86; Published online: 22 July 2013
}

A lthough previous studies indicate interracial differences in prostate cancer epidemiology based on gene expression profiles among patients from the United States, China and Japan, evidence at the genetic and phenotypic levels that these differences exist and manifest along ethnic lines has been sparse. Recent studies, however, suggest that genetic differences, such as the lower incidence of Chinese prostate cancers harboring TMPRSS2-ERG translocations compared to patients from Western countries, should be carefully considered in the context of genotypic and phenotypic differences among interracial groups. New, more efficient technologies need to be developed to validate genetic, gene expression and/or phenotypic differences associated with prostate cancer tissue specimens obtained from interracial groups, to establish reliable clinical standards that take racial/ethnic data into account to improve the diagnosis, prognosis and treatment of patients with prostate cancer.

Racial/ethnic differences in prostate cancer have become the focus of many epidemiologic and outcome research studies due to the wellrecognized differences in the annual death rate between African-Americans and CaucasianAmericans. African-Americans have a 2.4 times higher average annual death rate than Caucasian-Americans, and a 76\% higher rate of diagnosed prostate cancer. ${ }^{1}$ To explain such significant differences between AfricanAmericans and Caucasian-Americans, efforts have been made to compare serum prostatespecific antigen (PSA) and androgenic steroids such as testosterone and dihydrotestosterone levels between African-Americans and CaucasianAmericans. The results of these studies seem

Department of Medicine, Samuel Oschin Comprehensive Cancer Institute, Cedars-Sinai Medical Center, Los Angeles, CA 90048, USA

Correspondence: Dr HE Zhau (Haiyen.zhau@cshs.org) to suggest that African-Americans have 15\% higher PSA than Caucasian-Americans, based upon the SEARCH and Johns Hopkins databases adjusted to demographic and cancerspecific characteristics including prostate weight. $^{2}$ These differences could be related to the relative levels of sex steroids in the African-American and Caucasian-American populations. While adolescent non-Hispanic blacks did not have higher testosterone SBG (sex steroid binding globulins) and 17- $\beta$ estradiol levels than non-Hispanic whites, ${ }^{3}$ data show higher serum dihydrotestosterone and the dihydrotestosterone to testosterone ratios in African-Americans than CaucasianAmericans and Hispanics. ${ }^{4}$ The latter study found no difference in the level of serum testosterone among these three interracial groups. Because of well-known environmental influences on the incidence of prostate cancer among racial/ethnic groups after migration from Japan and China to the United States ${ }^{5-7}$ and the well-known fact that men castrated prior to puberty fail to develop benign or cancerous prostates, a series of studies have been conducted to document potential interracial differences in gene/environment interaction. For example, lower calcium absorption and modified singlenucleotide polymorphism in the $C D X-2$ binding site to the vitamin $\mathrm{D}$ receptor were commoner in Caucasian-Americans than African Americans, which may account for racial differences in cancer development. ${ }^{8}$ Racial/ethnic differences in CpG island methylation were found at birth. ${ }^{9}$ These results are supported by differences in the specific methylation of genes such as GSTP1, AR, RAR beta2, SPARC, TIMP3 and $N K X 2-5$ in which higher methylation was found in African-Americans than in Caucasian-Americans. ${ }^{10}$ The methylation differences found in adulthood could potentially be contributed by neonatal imprinting, as demonstrated in our early studies where we showed that both the growth of sex steroid-sensitive organs and their steroidmetabolizing enzymes in the target organs were affected by prior exposure of animals to testosterone or $17-\beta$-estradiol during the neonatal period. ${ }^{11-13}$ In addition to the report cited above characterizing racial/ethnic differences in prostate cancer among AfricanAmericans, Caucasian-Americans, Chinese and Japanese, numerous other attempts have been made to characterize the differences among Americans, Europeans, Africans and other Asian races. ${ }^{14-16}$ In this review, we will summarize our work highlighting interracial comparative studies of prostate cancer in the United States, China and Japan, focusing on gene expression differences pertinent to cell signaling networks involved in the development of castration-resistant prostate cancer (CRPC) and its subsequent dissemination to bone and soft tissues.

\section{COMPARATIVE RACIAL/ETHNIC STUDIES OF PROSTATE CANCER IN PATIENTS FROM THE UNITED STATES, CHINA AND JAPAN}

Although interracial differences in prostate cancer progression are well recognized, the underlying molecular and cellular mechanisms remain poorly defined. To establish the racial/ethnic differences in prostate cancer among patients from the United States, China and Japan, we conducted a comparative study of the histomorphological, immunohistochemical and molecular characterizations of unselected prostate cancer tissues obtained from United States, Chinese and Japanese men. In this cohort of prostate cancer tissues, we observed that $74.4 \%$ of the prostate cancers in Chinese men were poorlydifferentiated compared with $28.6 \%$ and $32.8 \%$ of the prostate cancers in United States and Japanese men, respectively. ${ }^{17}$ 
These histopathological differences among interracial groups cannot be attributed to patient age, clinical stage of the disease or methods of tissue sampling. Nor are these differences related to the patient's access to medical services or geographic backgrounds within the group of Chinese patients. Interestingly, significantly higher levels of tumor angiogenesis (2- to 4-fold), serotonin (2- to 20-fold) and bombesin (7- to 16-fold) but not chromogranin A were found in tissue specimens obtained from Chinese prostate cancer patients compared to those from the United States and Japan. ${ }^{17,18}$ Since tumors expressing angiogenic and neuroendocrine properties have been shown previously to be associated with increased aggressive behavior in human prostate cancer, ${ }^{19,20}$ we determined the interracial differences in p53 protein accumulation in the United States, Chinese and Japanese patient cohorts. We found that tumor suppressor p53 was present in $90.2 \%$ of the Chinese specimens, $17.4 \%$ of the Caucasian-Americans, $3.7 \%$ of the AfricanAmericans and $7.1 \%$ of specimens from Japanese men. We conducted a multivariate logistic regression analysis which demonstrated that $\mathrm{p} 53$ protein accumulation, angiogenesis and serotonin expression in the normal stromal area of the prostate gland correlate independently with Chinese versus non-Chinese patient populations. ${ }^{17,18}$ The results of this study could be explained by a number of possibilities: (i) the intrinsic differences of prostate cancer among Chinese, Japanese and Caucasian-American and African-American men are due to the heterogeneity of genetic or epigenetic regulatory factors; (ii) sampling bias due to the methods by which tumor specimens were obtained. This difference, however, cannot be attributed to the diagnosis of prostate cancer by serum PSA since these specimens were collected before serum PSA became a popular screening tool for prostate cancer; (iii) the gene expression profile of the prostate gland can be significantly modulated by the environmental, dietary or lifestyle characteristics of racial/ethnic groups; and (iv) the contribution of gene/environment interaction, in which some factors in the Chinese environment, culture, lifestyle or diet offer substantial protection against cancers such as prostate cancer that afflicts Western men. The higher proportion of Chinese men with poorly-differentiated prostate cancer could be due to protective factors in the environment, diet or lifestyle that prove to be effective initially, but can no longer prevent the progression of prostate cancer at an advanced stage, resulting in a higher proportion of prostate cancer cells 'escaping' from these preventive environment, diet or lifestyle factors and triggering the development of more aggressive prostate cancer. The latter possibility, however, unfortunately can no longer be examined in contemporary populations since dietary and cultural globalization has changed the Chinese and Japanese diet and lifestyle along with reported increases in the incidence of prostate cancer in Asian countries in recent decades. ${ }^{21-23}$

To correlate the levels of gene expression and the progression of cancer in different interracial groups better, we have developed a multiplexed quantum dot labeling (mQDL) method to investigate the cell-signaling pathways that have been associated with the development of CRPC and its subsequent progression to bone and soft tissue metastases.

\section{MQDL OF THE CELL-SIGNALING NETWORKS IN CRPC}

Semiconductive quantum dots (QDs) fluorescent nanoparticles have been used to detect relevant biomarkers expressed by cells, tissues and sera. ${ }^{24-26}$ The unique optical electronic properties of QDs include their narrow and symmetrical emission bands, size- and material- tunable light emission, high surface-to-volume ratio, photo stability, signal brightness and sensitivity, and simultaneous excitation of multiple fluorescence colors to detect multiple targets simultaneously at the single cell level. mQDL has become an attractive technology for the detection of cell signaling networks at the single cell level in cancer tissues and cells. ${ }^{24-29}$ We have further developed this technology using cell and tissue models of prostate cancer developed in our laboratory including human prostate cancer cells that exhibit transition to mesenchymal phenotype and gain substantial invasive migratory and metastatic potential. ${ }^{30,31} \mathrm{We}$ correlated quantitatively the expression of genes associated with prostate cancer progression and metastasis and the mQDL readout of different protein factors at the single cell level in both cell lines and xenograft tissues. This correlation involves quantitative assessment of RNAs by quantitative reverse transcription-polymerase chain reaction (qRT-PCR) and proteins by Western blot. The levels of expression of genes assessed by these biochemical methods were compared to those obtained by mQDL methods. The results of these studies clearly documented that differential gene expression as assessed by qRTPCR and Western blot can be correlated with the assessment of gene expression by mQDL, using a protocol reported by $\mathrm{Hu}$ et al. ${ }^{31}$ In this study, the intensity of fluorescence labeling of signal transduction protein in cells was assessed by a CRi spectra imaging system with Nuance 3.0 software. For each field of cancer tissue, serial images were acquired at $10-\mathrm{nm}$ wavelength intervals from 450 to $800 \mathrm{~nm}$ range chosen to correspond to the active fluorescent QDs. This method generates an unprocessed image 'cube' as a stack of 36 separate images with each image containing the complete spectral information for every pixel at that given wavelength. The acquired images are then subjected to deconvolution or unmixing to extract specific labeling by a given $\mathrm{QD}$, based on their optimal emission wavelength. A spectral library for 565, 585, $605,625,655$ and $705 \mathrm{~nm}$ was built for deconvolution. Based on this protocol, we focused our attention on assessing RANKL-RANK convergent signaling with the $H G F-c-M e t$ signaling pathway, with activation of these signaling pathways by hypoxia through the induction of a transcription factor, HIF1- $\alpha$, its target gene vascular endothelial growth factor (VEGF) and a VEGF coreceptor neuropilin-1 (NRP-1), and survival genes such as phosphorylated (p), NF- $\kappa B$ or $p-c-M e t$ and $M c l-1$. Using a highly metastatic human prostate cancer cell model, we determined that this signaling pathway is responsible for driving epithelial-mesenchymal transition and CRPC progression. After establishing and validating $\mathrm{mQDL}$ in human prostate cancer cell lines and a CRPC xenograft human prostate cancer animal model, ${ }^{31}$ we conducted an mQDL analysis of primary human prostate cancer tissues from patients with known survival, to identify whether RANKL-RANK convergence signaling with $H G F-c-M e t$ and $V E G F-N R P-1$ correlated with overall survival of prostate cancer patients, using tissues collected from patients with diverse racial and ethnic backgrounds. In this study, we reconfirmed the racial/ethnic differences in biomarkers associated with the development of lethal prostate cancer among these specimens. The results can be summarized as follows: (i) while convergent signaling among RANKL-RANK, HGF-c-Met and VEGF$N R P-1$ seemed to be linked by a pair-wise correlogram plot, there are differences among interracial groups of Caucasian-Americans, African-Americans and Chinese with respect to their predictive values for patient overall survival; (ii) Kaplan Meier plots show that the level of RANKL and NRP-1 expression, expressed as total (cytosolic plus nuclear) or individual subcellular fractions, at the single cell level in primary prostate cancer specimens 
is an independent predictor of overall survival $(P<0.05)$ for Caucasian-Americans. Patients with high RANKL and NRP-1 expression have a mean survival of $8-10$ months in contrast to patients with low expression who lived 120-130 months. A correlogram plot with pairwise correlations between Gleason scores and biomarkers showed that the expression of $p-N F-\kappa B$, HIF-1- $\alpha$, VEGF, NRP-1 and p-c-Met was not correlated with Gleason scores. We found that RANKL and NRP-1 expression by univariate analysis, while not correlated with patient Gleason score, offered predictive value for the overall survival of CaucasianAmericans; and (iii) In contrast to Caucasian-Americans, we found that $\mathrm{p}$-cMet in the nucleus and Gleason score of African-Americans by multivariate analysis and total (nucleus and cytosol) or nuclear or cytosolic NRP-1 and cytosolic VEGF expression in the Chinese population by univariate analysis correlated with the overall survival of prostate cancer patients. These results collectively suggest differences in biomarker expression among men of different racial/ethnic backgrounds. Therefore, the use of these biomarkers for the prediction of progression and survival in patients diagnosed with prostate cancer needs to take the racial and ethnic background of the patient into account.

\section{SUMMARY AND CONCLUSIONS}

Increasing evidence suggests that racial/ethnic differences in prostate cancer could be caused by gene-environment interaction. These differences at the single cell level can be most effectively analyzed by the development of sensitive technologies for assessing quantitatively the levels of gene expression (proteins or RNAs) at a single cell. Here we described how the levels of protein expression by the use of mQDL method could provide powerful predictive values for survival using prostate cancer tissues collected from patients at the time of disease diagnosis and surgery. We found that the RANKL-RANK, HGF-cMet, and VEGF-NRP-1 signaling pathways are of special importance for prognosis in patients with prostate cancer. Further, we found that racial/ethnic differences exist in the ability of these pathway-related biomarkers to predict survival. Our findings and other published results suggest that in order to develop highly efficient personalized diagnosis, prognosis and treatment in prostate cancer, it is vital to develop sensitive technologies that can assess genetic, gene expression and phenotypic differences at the single-cell level in prostate cancer specimens obtained from patients with different ethnic backgrounds.

\section{COMPETING FINANCIAL INTERESTS}

All authors declare that there are no competing financial interests.

\section{ACKNOWLEDGMENTS}

This work is supported by research grants from the Prostate Cancer Foundation and NIH/NCI

(Nos. 2PO1CA098912 and 1RO1CA122602)

awarded to Leland W K Chung, who is an endowed Board of Governors Cancer Research Chair, and a DoD grant awarded to Haiyen E Zhau.

1 Taksler GB, Keating NL, Cutler DM. Explaining racia differences in prostate cancer mortality. Cance 2012; 118: 4280-9.

2 Mavropoulos JC, Partin AW, Amling CL, Terris MK, Kane $\mathrm{CJ}$ et al. Do racial differences in prostate size explain higher serum prostate-specific antigen concentrations among black men? Urology 2007; 69: 1138-42.

3 Lopez DS, Peskoe SB, Joshu CE, Dobs A, Feinleib M et al. Racial/ethnic differences in serum sex steroid hormone concentrations in US adolescent males. Cancer Causes Control 2013; 24: 817-26.

4 Litman HJ, Bhasin S, Link CL, Araujo AB, McKinlay JB. Serum androgen levels in black, Hispanic, and white men. J Clin Endocrinol Metab 2006; 91 4326-34.

5 Luo W, Birkett NJ, Ugnat AM, Mao Y. Cancer incidence patterns among Chinese immigrant populations in Alberta. J Immigr Health 2004; 6 : 41-8.

6 Maskarinec G, Noh JJ. The effect of migration on cancer incidence among Japanese in Hawaii. Ethn Dis 2004; 14: 431-9.

7 Singh GK, Miller BA. Health, life expectancy, and mortality patterns among immigrant populations in the United States. Can J Public Health 2004; 95 I14-21.

8 Rowland GW, Schwartz GG, John EM, Ingles SA Protective effects of low calcium intake and low calcium absorption vitamin $\mathrm{D}$ receptor genotype in the California Collaborative Prostate Cancer Study. Cancer Epidemiol Biomarkers Prev 2013; 22: 16-24.

9 Adkins RM, Krushkal J, Tylavsky FA, Thomas F. Racia differences in gene-specific DNA methylation levels are present at birth. Birth Defects Res A Clin Mol Teratol 2011; 91: 728-36.

10 Kwabi-Addo B, Wang S, Chung W, Jelinek J, Patierno $\mathrm{SR}$ et al. Identification of differentially methylated genes in normal prostate tissues from African American and Caucasian men. Clin Cancer Res 2010; 16: 3539-47.

11 Chung LW, Ferland-Raymond G. Differences among rat sex accessory glands in their neonatal androgen dependency. Endocrinology 1975; 97: 145-53.

12 Chung LW, Chao $\mathrm{H}$. Neonatal imprinting and hepatic cytochrome P-450. I. Comparison of testosterone hydroxylation in a reconstituted system between neonatally imprinted and nonimprinted rats. $\mathrm{Mol}$ Pharmacol 1980; 18: 543-9.

13 Tilghman SM. The sins of the fathers and mothers: genomic imprinting in mammalian development. Cell 1999; 96: 185-93.

14 Zeigler-Johnson CM, Spangler E, Jalloh M, Gueye SM Rennert $\mathrm{H}$ et al. Genetic susceptibility to prostate cancer in men of African descent: implications for global disparities in incidence and outcomes. Can J Urol 2008; 15: 3872-82.

15 Jemal A, Center MM, DeSantis C, Ward EM. Global patterns of cancer incidence and mortality rates and trends. Cancer Epidemiol Biomarkers Prev 2010; 19: 1893-907.

16 Center MM, Jemal A, Lortet-Tieulent J, Ward E, Ferlay $J$ et al. International variation in prostate cancer incidence and mortality rates. Eur Urol 2012; 61 1079-92.

17 Zhau HE, Zhao LS, Chung LW, Chen BQ, Troncoso P et al. Comparative studies of prostate cancers among United States, Chinese, and Japanese patients: characterization of histopathology, tumor angiogenesis, neuroendocrine factors, and $\mathrm{p} 53$ protein accumulations. Urol Oncol 1995; 1: 51-63.

18 Zhau HE, Zhao LS, Chen BQ, Kojima M. Interracial comparative study of prostate cancer in the United States, China, and Japan. Journa of cellular biochemistry. Supplement 1997; 2829: 182-5.

19 Borre M, Nerstrom B, Overgaard J. Association between immunohistochemical expression of vascular endothelial growth factor (VEGF), VEGF-expressing neuroendocrine-differentiated tumor cells, and outcome in prostate cancer patients subjected to watchful waiting. Clin Cancer Res 2000; 6: 1882-90.

20 Chevalier S, Defoy I, Lacoste J, Hamel L, Guy L et al. Vascular endothelial growth factor and signaling in the prostate: more than angiogenesis. Mol Cell Endocrinol 2002; 189: 169-79.

21 Kuo YJ, Lin SF, Chang YH, Pan CC. Trends in prostate needle biopsy diagnosis. a ten year experience of a medical center in Taiwan. Pathol Int 2012; 62 191-8.

22 Sim HG, Cheng CW. Changing demography of prostate cancer in Asia. Eur J Cancer 2005; 41: 834-45.

23 Zhang J, Dhakal IB, Zhao Z, Li L. Trends in mortality from cancers of the breast, colon, prostate, esophagus, and stomach in East Asia: role of nutrition transition. Eur J Cancer Prev 2012; 21 480-9.

24 Mansur HS. Quantum dots and nanocomposites. Wiley interdisciplinary reviews. Nanomed Nanobiotechnol 2010; 2: 113-29.

25 Xing Y, Rao J. Quantum dot bioconjugates for in vitro diagnostics \& in vivo imaging. Cancer Biomarkers 2008; 4: 307-19.

26 Zrazhevskiy P, Gao X. Quantum dot imaging platform for single-cell molecular profiling. Nat Commun 2013; 4: 1619.

27 Alivisatos AP, Gu W, Larabell C. Quantum dots as cellular probes. Annu Rev Biomed Eng 2005; 7 55-76.

28 Hotz CZ. Applications of quantum dots in biology: an overview. Methods Mol Biol 2005; 303: 1-17.

29 Medintz IL, Uyeda HT, Goldman ER, Mattoussi H. Quantum dot bioconjugates for imaging, labelling and sensing. Nat Mater 2005; 4: 435-46.

30 Xu J, Wang R, Xie ZH, Odero-Marah V, Pathak S et al. Prostate cancer metastasis: role of the host microenvironment in promoting epithelial to mesenchymal transition and increased bone and adrenal gland metastasis. Prostate 2006; 66 : 1664-73.

31 Hu P, Chu GC, Zhu G, Yang H, Luthringer D et al. Multiplexed quantum dot labeling of activated c-Met signaling in castration-resistant human prostate cancer. PIOS ONE 2011; 6: e28670. 